\title{
The Effect of Delayed-Dormant Chemical Treatments on Demethylation Inhibitor (DMI) Sensitivity in a DMI-resistant Population of Venturia inaequalis
}

Zachary A. Frederick, Department of Plant Pathology, Washington State University, Pullman 99164; and Sara M. Villani and Kerik D. Cox, Department of Plant Pathology and Plant-Microbe Biology, Cornell University, Geneva NY 14456

\begin{abstract}
Frederick, Z. A., Villani, S. M., and Cox, K. D. 2015. The effect of delayed-dormant chemical treatments on demethylation inhibitor (DMI) sensitivity in a DMI-resistant population of Venturia inaequalis. Plant Dis. 99:1751-1756.

Demethylation inhibitor (DMI) fungicides are an effective means to manage apple scab caused by Venturia inaequalis. Unfortunately, practical resistance to DMI fungicide chemistries is prevalent in populations in New York and the New England states. Management practices that delay the development of DMI resistance in $V$. inaequalis populations are highly desired by regional apple producers. Trials were conducted in a New York apple orchard during the 2011 and 2012 growing seasons to determine the impact of delayed-dormant (after bud break, but prior to green tissue) chemical treatments on the DMI sensitivity of a $V$. inaequalis population with stable resistance to DMI fungicides. Delayed-dormant treatment programs consisted of either an application of a copper fungicide, a manganese sanitation product, a DMI fungicide (myclobutanil), or no fungicide. Sensitivity to the DMI fungicide myclobutanil was evaluated for a minimum of $25 \mathrm{~V}$. inaequalis single

lesion conidial isolates from each of four replicated treatment blocks. In both years, mean percent relative growth on myclobutanil amended media for $V$. inaequalis isolates from the copper treatment program were significantly $(P<0.05)$ lower than isolates from blocks did not receive a delayed dormant fungicide treatment. The effect of the manganese treatment was inconsistent between years. V. inaequalis isolates collected from the myclobutanil treatment program were not significantly $(P>0.05)$ different in myclobutanil sensitivity from isolates collected from the blocks that did not receive a delayed dormant fungicide treatment. Overall, the results suggest that delayed dormant treatments of copper may favorably impact the myclobutanil sensitivity for a population of $V$. inaequalis with resistance to DMI fungicides, and should be considered as a standard management practice in apple production.
\end{abstract}

Apple scab, caused by the ascomycete fungal pathogen Venturia inaequalis (Cooke) Winter, is one of the most economically important fungal disease affecting apple production worldwide (Agrios 2005; Holb et al. 2003; MacHardy 1996; MacHardy et al. 2001). Infections are most severe in the temperate climates of the apple production regions in the eastern United States where cool wet weather conditions consistently favor infections in the spring (Agrios 2005; Holb et al. 2003; MacHardy 1996; MacHardy et al. 2001; Merwin et al. 1994). Such favorable environmental conditions require a fungicide management program from bud break to early summer (MacHardy 1996; MacHardy et al. 2001).

Apple producers in the northeastern United States often begin apple scab management programs prior to bud break. Management practices during dormancy aim to reduce overwintering inoculum by shredding the leaf litter with specialized equipment or by making an application of urea to degrade leaf litter on the orchard floor (MacHardy 1996; Sutton et al. 2000). In addition to these cultural practices, copper is sometimes used before or at bud break to reduce overwintering fire blight inoculum (Norelli et al. 2003), and is effective for the management of apple scab (Holb et al. 2003; Montag et al. 2006). Because of deleterious effects on fruit finish such as fruit russet and phytotoxic effects to the foliage (Jama and Lateur 2007; Montag et al. 2006), copper is usually not applied during the time when leaves and fruit are developing. However, it is sometimes applied just after bud break and prior to the onset of green tissue. This type of application is referred as a delayed-dormant application (Singer and Cox 2010). In addition to the potential effects on overwintering fire blight inoculum, it is anecdotally believed that delayed-dormant applications of copper would affect overwintering apple scab inoculum

Corresponding author: Kerik D. Cox, E-mail: kdc33@cornell.edu

Accepted for publication 6 May 2015.

http://dx.doi.org/10.1094/PDIS-12-14-1253-RE

(C) 2015 The American Phytopathological Society surviving as conidia in bud scales. Aside from copper, it is not known if other novel metal cation products would have similar effects on overwintering apple scab inoculum.

Demethylation inhibitor (DMI) fungicides have been utilized in apple production to manage several key diseases of apple for more than 30 years (Gilpatrick 1982; Köller et al. 1997). However, due to the highly specific mode of action, DMI fungicides are prone to the development of practical resistance (Gilpatrick 1982; Ma and Michailides 2005) by the pathogen. Practical resistance can be defined as greatly diminished levels of disease control resulting from the selection of population members with resistance phenotypes insufficiently controlled by proper fungicide application (Köller 1991). Considering the utility of DMI fungicides and the problem that DMI resistance poses to apple scab management, there is interest to identify management practices that reduce the persistence of practical DMI resistance in orchard populations of $V$. inaequalis. To that end, Pfeufer and Ngugi (2012) conducted a survey study to examine the correlation between different orchard management practices and the presence of DMI-resistant $V$. inaequalis. It was observed that growers who made a delayed dormant application of copper were nearly twice as likely to have DMI-sensitive $V$. inaequalis populations in their apple orchards (Pfeufer and Ngugi 2012). However, the direct impact of delayed-dormant copper application on the fungicide sensitivity of the surviving $V$. inaequalis populations is unknown. It is not known if such copper use could affect the sensitivity to fungicides prior to the onset of practical resistance. Additionally, it is not known whether other metal cation solutions, such as manganese, would have an effect on the fungicide sensitivity of $V$. inaequalis populations.

Because of the central role of fungicide resistance in apple scab management failures in the northeastern United States (Köller et al. 1997; Lesniak et al. 2011), detailed investigations are warranted to determine if delayed-dormant applications would have any effect on the fungicide sensitivity of an orchard population of $V$. inaequalis. We intended to examine the effect of delayed-dormant fungicide treatments on the sensitivity of a $V$. inaequalis population to a fungicide class to which the population has practical resistance. We also 
wished to determine if delayed-dormant applications of another metal cation solution (manganese) would have a similar effect to copper on population sensitivity to DMI fungicides. Such information would have implications regarding the use of delayed-dormant fungicide treatments as a form of fungicide resistance management in orchard populations of $V$. inaequalis.

\section{Materials and Methods}

Orchard trial to evaluate the effect of delayed dormant fungicide application on the DMI sensitivity of $\boldsymbol{V}$. inaequalis. Trials were conducted in an orchard at the New York State Agricultural Experiment Station in Geneva, NY, during the 2011 and 2012 apple production seasons. The orchard consisted of 35-year-old paired interplanted trees of 'McIntosh' and 'Cortland' apple on M.M. 111 rootstock. The orchard was selected because it would allow us to test the effect of delayed-dormant applications on a $V$. inaequalis population with practical resistance to the DMI fungicide myclobutanil (Cox et al. 2009, 2010). This orchard was also selected to examine the effects of delayed-dormant applications on sensitivity to dodine, another fungicide with a quantitative resistance response, to which this $V$. inaequalis population was confirmed to be sensitive (Cox et al. 2011, 2012). Delayed-dormant treatments were made during the silver tip phenological stage (8 April 2011 and 8 March 2012) and consisted of one of the following: Badge $\times 2$ (copper hydroxide and copper oxychloride, 1,066.66 g/ha, Isagrow USA, Morrisville, NC), F2 Permanganate (manganese cation, 3,055 liters/ha, F2 Industries, Smyrna, TN), Rally 40WSP (DMI fungicide, myclobutanil, $333.33 \mathrm{~g} / \mathrm{ha}$, Dow Agrosciences, Indianapolis, IN), or no delayeddormant fungicide application ("no fungicide"). All delayeddormant treatments were applied to four replicate blocks (each block approximately 1.2 ha in 2011 and 1.0 ha in 2012) at different locations in the orchard between years. Applications were made in approximately 2,800 liters of water per hectare using an AA2 GunJet handgun (TeeJet Technologies, Wheaton, IL) at approximately $2,000 \mathrm{kPa}$. Both the trees and the leaf litter underneath were treated to the point where uniform saturation of both the tree canopy and the ground was reached. Following the delayed-dormant applications, a standard maintenance program consisting of captan $(2.8 \mathrm{~kg} / \mathrm{ha})$ (Captan 80 WDG, Arysta LifeScience Company, Cary, NC) mixed with mancozeb (3.3 kg/ha) (Penncozeb 75DF, United Phosphorus Inc, King of Prussia, PA) was applied to all treatment blocks to protect against apple scab infection during the period of typical susceptibility (i.e., green tip to second cover). These maintenance applications were made on 7- to 10-day intervals from tight cluster (2 May 2011, 28 March 2012) through second cover (22 June 2011, 24 May 2012) in each trial year. During the summer (third to seventh cover), all of the treatment blocks received applications of captan (5.6 kg/ha) (Captan 80 WDG, Arysta LifeScience Company). These summer cover applications were made to the entire orchard on 14- to 21-day intervals from third (8 July 2011, 14 June 2012) through seventh cover (9 September 2011, 30 August 2012) in each year.

Data on rainfall, hours of leaf wetness, predicted ascospore maturity, and predicted apple scab infection events were collected from the Network for Environment and Weather Applications (NEWA) (http://newa.cornell.edu/index.php?page=apple-diseases) for the delayed-dormant application date in each year that the trials were conducted. The weather station from which the service collects data are on site.

In vitro fungicide sensitivity of $V$. inaequalis single lesion conidial isolates to myclobutanil and dodine. In vitro sensitivity to the DMI fungicide myclobutanil was determined for collections of single-lesion conidial isolates using a previously published relative growth assay for $V$. inaequalis (Köller et al. 2004; Olaya and Koller 1999). On 28 May 2011 and 7 May 2012, 100 leaves with young ( $<1$ week old), primary $V$. inaequalis lesions were collected from the 'McIntosh' trees from each replicated delayed dormant treatment block. Leaves were collected at this time as they represent lesions resulting from infection periods most closely associated with the delayed dormant treatment applications. Collections made from later in the season would represent infections occurring long after the delayed dormant treatment applications and could potentially represent secondary infection events. The leaves were collected from all of the trees throughout the plots and from the exterior and interior of the tree canopies. To establish single conidial isolates, leaf lesions $(n>$ 25) distant from other colonies, representing infections arising from a single spore, were excised using a cork borer (7 mm diameter), placed in $1.2 \mathrm{ml}$ of distilled water, and manually vigorously shaken for $60 \mathrm{~s}$ to dislodge conidia from the lesion. The resulting conidial suspensions were evaluated for fungicide sensitivity using microscopy aided mycelial relative growth assay, as described previously (Köller et al. 1997). In short, $100 \mu l$ of the conidial suspension $\left(10^{4}\right.$ conidia/ml $)$ was applied to the surface of potato dextrose agar (PDA; Difco Laboratories, Detroit, MI) medium amended with a published discriminatory dose of myclobutanil $(0.1 \mu \mathrm{g} / \mathrm{ml}$ analytical standard; Sigma-Aldrich, St. Louis, MO) (Köller et al. 1997) and to medium without myclobutanil. All PDA medium was amended with streptomycin sulfate (50 $\mu \mathrm{g} / \mathrm{ml}$, Sigma-Aldrich) and chloramphenicol (50 $\mu \mathrm{g} / \mathrm{ml}$, Sigma-Aldrich) to suppress yeast and bacterial growth. Isolates were incubated for 7 days in the light at 23 to $25^{\circ} \mathrm{C}$, and five single-conidia colonies were measured at the point of their largest expansion using a SPOT Idea digital camera using the SPOT Imaging Basic software package (Diagnostic Instruments Inc., Sterling Heights, MI) attached to an Olympus SZX12 stereo scope (70-120x; Olympus America Inc., Center Valley, PA). Single-conidia colonies were selected on the basis of being separated from other colonies by more than $5 \mathrm{~mm}$. Fungicide sensitivity to myclobutanil for each isolate was expressed as mean percent relative growth (\%RG) as previously described (Köller et al. 2004), with relative growth being defined as the growth of an isolate on a medium amended with a fungicide relative to growth on a medium without a fungicide.

Sensitivity to dodine, a fungicide to which the population did not have practical resistance, was also determined. This was evaluated in a manner identical to that of myclobutanil with the exception that a discriminatory dose of $0.2 \mu \mathrm{g} / \mathrm{ml}$ (dodine analytical standard; Sigma-Aldrich) was used as previously described for $V$. inaequalis (Köller et al. 1999).

Logarithmic and arcsine data transformations were performed on isolate sensitivities (\%RG) for myclobutanil and dodine to determine which transformation best stabilized the variances and approximated normality. The distribution of sensitivity responses for each fungicide and transformation was analyzed for normality by the ShapiroWilk test using the continuous fit test of JMP v.9.0 (SAS Institute, Cary, NC). The effect of delayed dormant treatment on fungicide sensitivity was determined using generalized linear mixed models with the GLIMMIX procedure of SAS v9.3 (SAS Institute). Differences in the mean \% RG of isolates between delayed dormant treatment programs was determined using the 'lsmeans' statement of GLIMMIX at the 5\% level of significance.

In vitro growth, sporulation, and copper sensitivity in $V$. inaequalis isolates from delayed dormant treatments and DMI sensitivity phenotypes. In addition to evaluating myclobutanil and dodine sensitivity, a subsample of isolates from each delayed dormant treatment and DMI sensitivity phenotype were further characterized for fitness in terms of in vitro growth rate, sporulation, and sensitivity to copper. We examined 44 isolates from each of the four delayed dormant treatments with equal representation of DMIsensitivity phenotypes (see below) and the 2011 and 2012 seasons. For the purpose of the examining isolate fitness in regards DMI sensitivity, isolates selected from the delayed dormant treatments classified into DMI sensitivity phenotypes. Isolates with \% RG values $>75$ on myclobutanil amended medium (see section above) were classified as DMI-resistant (DMI-R), while isolates with \%RG values $<75$ were classified as DMI-sensitive (DMI-S). Sensitivity to copper was evaluated in a manner identical to that of myclobutanil with the exception that isolates were cultured on casitone yeast extract (CYE) agar because of its limited copper binding potential, which was amended with a discriminatory dose of $125 \mu \mathrm{g} / \mathrm{ml} \mathrm{CuSO} \cdot 5 \mathrm{H}_{2} \mathrm{O}$ (Sigma-Aldrich) as previously described (Loper et al. 1991). 


\section{Results}

The prevailing weather conditions and ascospore maturity during application. According to the NEWA service, the average temperature on the 2011 delayed-dormant application date of 8 April ranged from 1 to $9.5^{\circ} \mathrm{C}$ while temperatures ranged between 11.6 and $23.4^{\circ} \mathrm{C}$ on the 2012 delayed-dormant application date of 18 March. There was no rain in the three days preceding the 2011 application, but there was $3 \mathrm{~cm}$ of rain over the course of the three days prior to the 2012 application. There was also $24 \mathrm{~h}$ of leaf wetness in the form of precipitation following the 2012 application. Using a weather-predicted biofix, the ascospore maturity model (Gadoury and MacHardy 1982) predicted that $1 \%$ of the ascospores were mature on the date of the delayed dormant treatments for the 2011 season. In the 2012 trial, approximately $2 \%$ of the ascospores were mature at the time of the delayed dormant application. At the times of application in 2011 and 2102, no infection events had been predicted by the NEWA system.

The effect of delayed-dormant treatment on in vitro sensitivity of $\boldsymbol{V}$. inaequalis isolates to myclobutanil. In 2011, the \% RG for isolates on myclobutanil-amended medium ranged from 0.0 to $157.0 \%$ with the mean \%RGs of the isolates being the lowest and highest in the manganese treatment ( $\mathrm{F} 2$ permanganate) program $(53.9 \pm 6.8)$ and the "no fungicide" treatment program $(88.7 \pm 4.2)$, respectively (Fig. 1A). There was a significant effect of delayed-dormant treatment on in vitro sensitivity of $V$. inaequalis isolates to myclobutanil $(P \leq 0.0001)$. The mean \%RG on myclobutanil-amended medium for isolates from the copper treatment was significantly lower than the "no fungicide" treatment $(P=0.0015$, Fig. 1A). Along these

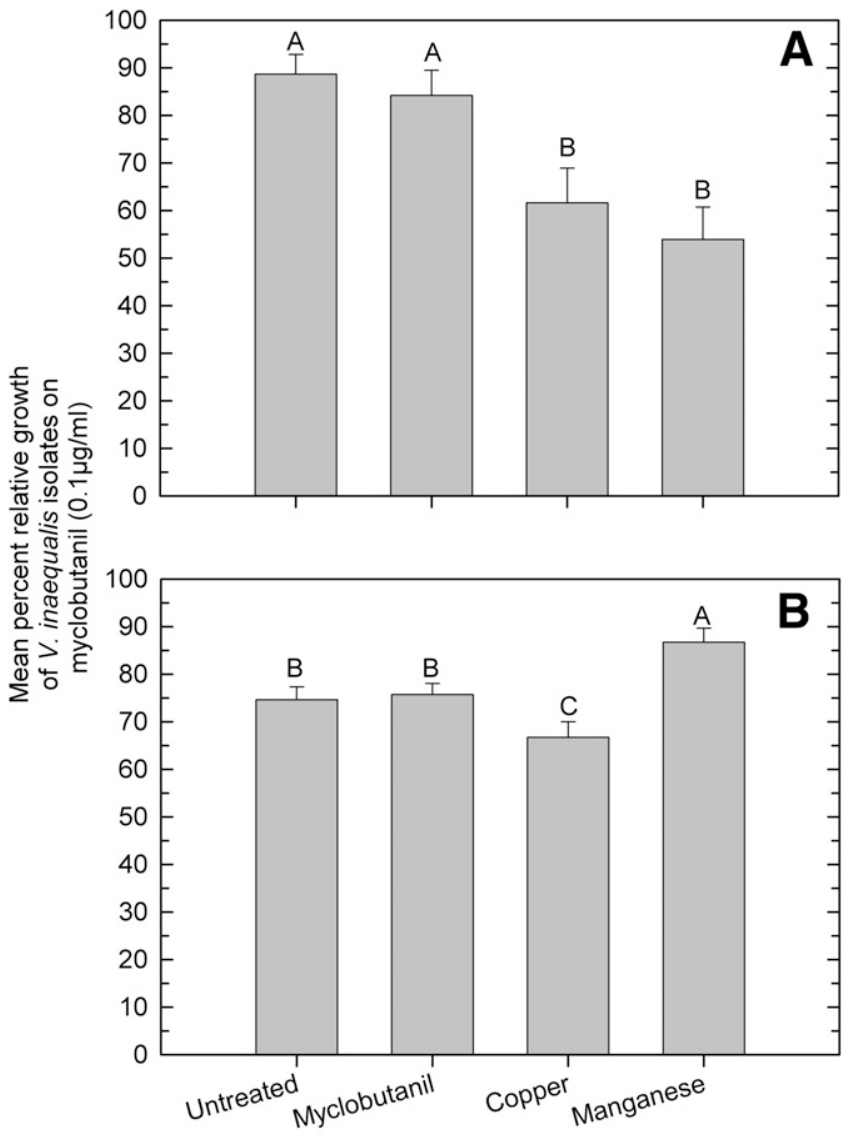

Delayed-dormant treatment

Fig. 1. The in vitro fungicide sensitivity of Venturia inaequalis isolates to myclobutanil for each delayed dormant treatment programs for the A, 2011 and B, 2012 trial. Bars represent the mean and standard error of percent relative growth values of $V$. inaequalis isolates from each replicated treatment block. Treatments denoted by the same letter lack statistical significance $(\alpha=0.05)$ among adjusted estimated mean incidences. lines, more than $50 \%$ of the isolates from the "no fungicide" treatment had \% RG values over $90 \%$ (Fig. 2A). By comparison, approximately $10 \%$ of the isolates from the copper treatment had \% RG values over $90 \%$. Interestingly, the mean $\%$ RG was the lowest for isolates from the manganese (F2 permanganate) treatment, which was also significantly different from the "no fungicide" treatment $(P \leq 0.0001$, Fig. 1A). There was no significant difference in mean $\%$ RG between isolates from the myclobutanil (Rally $40 \mathrm{WSP}$ ) treatment and those from the "no fungicide" treatment $(P=0.6148)$.

In 2012 , the $\%$ RG of isolates on myclobutanil-amended medium ranged from 0.1 to $116.7 \%$ with the mean \%RGs of the isolates being the lowest and highest on copper $(67 \pm 3.3)$ and manganese ( $\mathrm{F} 2$ permanganate) $(84 \pm 3.0)$ treatment, respectively (Fig. 1B). Isolates from the "no fungicide" treatment had a mean $\%$ RG of $74.6 \pm 2.7$. Similar to 2011 , there was a significant $(P=0.0003)$ effect of delayed dormant treatment on the sensitivity of $V$. inaequalis isolates to myclobutanil in 2012. In 2012, the mean \%RG of isolates was lowest for the copper treatment, which was significantly different from the "no fungicide" treatment $(P=0.0146$, Fig. 1B). Along these lines, approximately $47 \%$ of the isolates from the "no fungicide" treatment had \%RG values over $90 \%$ (Fig. 2B). By comparison, only approximately $15 \%$ of the isolates from the copper treatment had \% RG values over $90 \%$. In contrast to the results from 2011, the mean $\%$ RG in 2012 was the highest for isolates from the manganese (F2 permanganate) treatment. Similar to observations from 2011, there was no

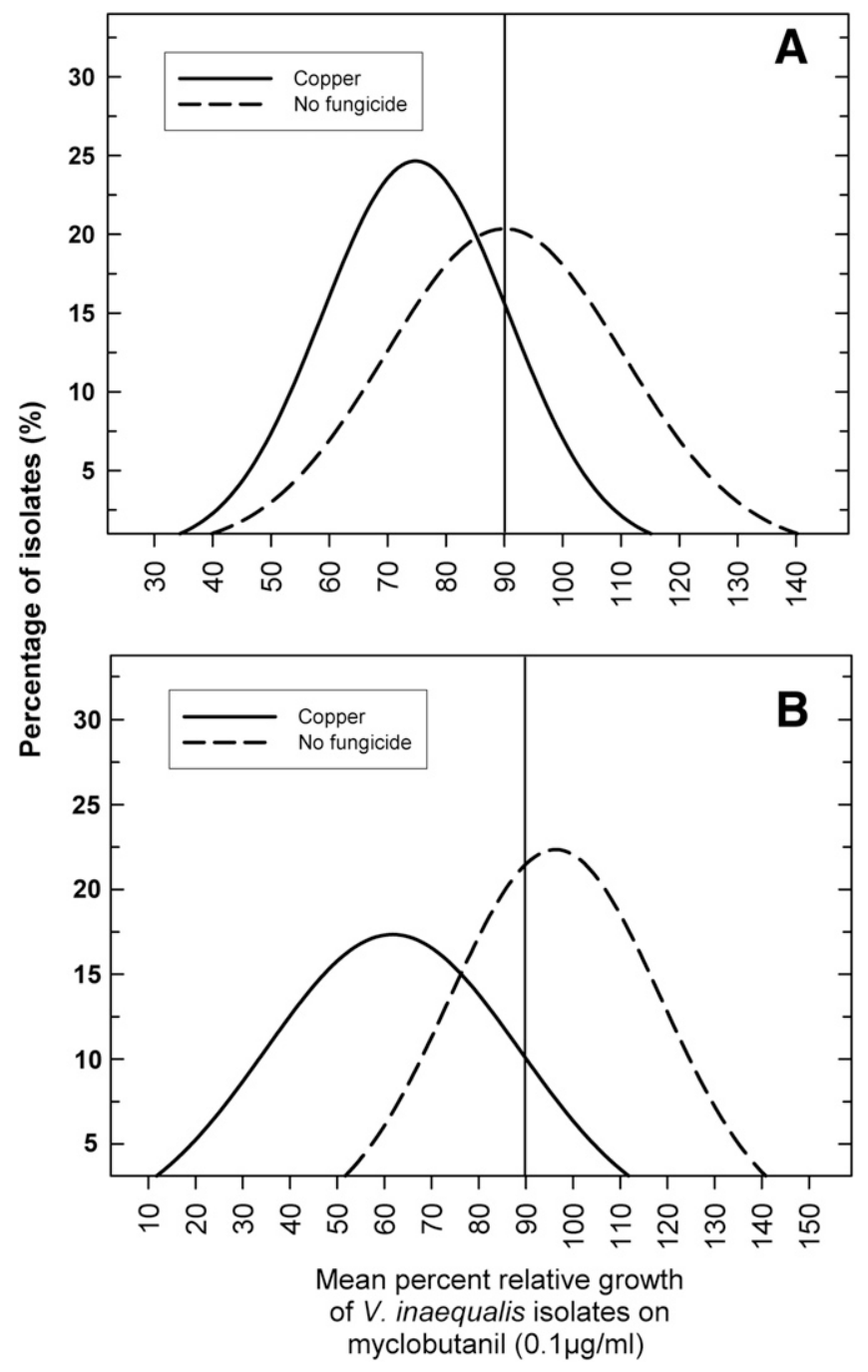

Fig. 2. Sensitivity distributions for Venturia inaequalis isolates to myclobutanil in vitro. Isolates were collected from the copper treatment program blocks and the blocks that received no fungicide in the A, 2011 and B, 2012 trial. Fungicide sensitivity is expressed as mean of percent relative growth values for $V$. inaequalis isolates collected across all replicate treatment blocks. 
significant difference $(P=0.7910)$ in mean $\%$ RG between isolates from the myclobutanil (Rally 40 WSP) treatment and those from the "no fungicide" treatment program in 2012.

The effect of delayed dormant treatment on in vitro sensitivity of $V$. inaequalis isolates to dodine, a fungicide to which the population was not resistant. In 2011, the \% RG of isolates on dodineamended medium ranged from 0.0 to $169.4 \%$ with the mean $\%$ RGs of the isolates being the lowest and highest in the copper $(17.2 \pm 3.3)$ and manganese ( $\mathrm{F} 2$ permanganate) $(26.1 \pm 3.1)$ treatments, respectively (Fig. 3A). Similarly in the 2012 trial, the $\%$ RG of isolates on dodine-amended medium ranged from 0.0 to $112.2 \%$ with the mean $\%$ RGs of the isolates being the lowest and highest in the "no

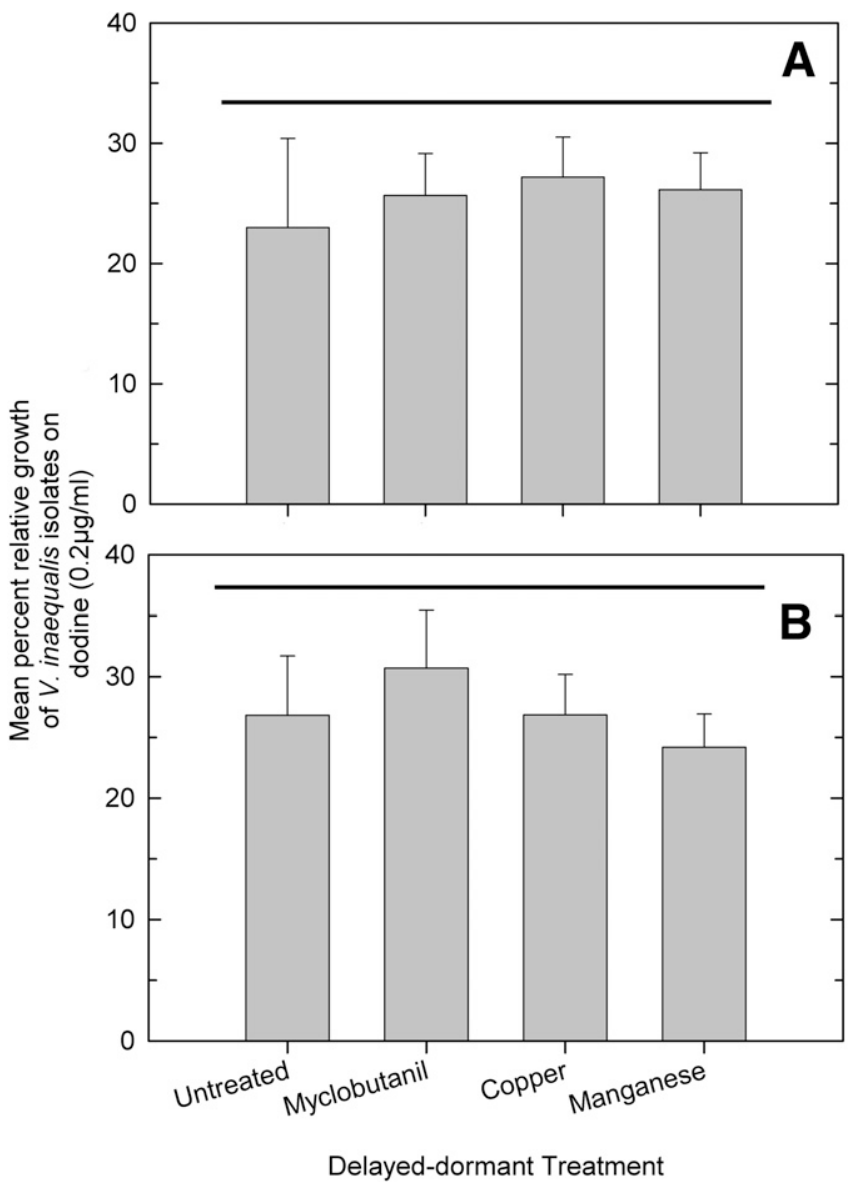

Fig. 3. The in vitro fungicide sensitivity of Venturia inaequalis isolates to dodine for each delayed dormant treatment programs for the A, 2011 and B, 2012 trial. Bars represent the mean and standard error of percent relative growth values of $V$. inaequalis isolates from each replicated treatment block. The straight line across the top of the bars indicates a lack of statistical significance $(\alpha=0.05)$ among adjusted estimated mean incidences. fungicide" (24.2 \pm 2.7$)$ and myclobutanil (Rally 40 WSP) $(34.7 \pm$ 4.7) treatments, respectively (Fig. 3B). Overall, there was no significant effect of delayed-dormant chemical treatment on sensitivity of $V$. inaequalis isolates to dodine in either year $(P=0.5938$ in 2011 ; $P=0.2038$ in 2012).

In vitro growth, sporulation, and copper sensitivity in $V$. inaequalis isolates from delayed dormant treatments and DMI sensitivity phenotypes. Across all delayed dormant treatments and DMI sensitivity phenotypes, the mean growth rates and mean sporulation of isolates ranged from 415.3 to 440.8 and 38.8 to 42.8 , respectively (Table 1$)$. There were no significant differences $(P>0.05)$ in growth rate or sporulation for DMI-R and DMI-S isolates or isolates collected from different delayed dormant treatments. Copper sulfate $\left(\mathrm{CuSO}_{4} \cdot 5 \mathrm{H}_{2} \mathrm{O}\right)$ at $125 \mu \mathrm{g} \mu \mathrm{g} / \mathrm{ml}$ had an impact on isolate growth with the mean growth rates ranging from 252.0 to 295.0 across all treatment conditions and DMI sensitivity phenotypes (Table 1). Similarly, to that observed for non-amended medium, there were no significant differences $(P>0.05)$ in growth rate for DMI-R and DMI-S isolates or isolates collected from different delayed dormant treatments.

\section{Discussion}

Delayed-dormant applications of copper resulted in $V$. inaequalis isolates (population) with higher mean sensitivity to myclobutanil (lower mean \%RG) than those from untreated plots. This corroborates the observations of Pfeufer and Ngugi (2012), who found that growers who reported using delayed-dormant applications of copper were nearly twice as likely to have $V$. inaequalis populations shifted toward DMI sensitivity compared with growers who had not reported using delayed-dormant applications of copper. In the present study, we recovered fewer highly resistant isolates from the plots receiving copper treatments compared with those left untreated. Indeed, we found that only 10 to $15 \%$ of the isolates from the blocks receiving a delayed dormant application of copper had mean \%RGs $>90 \%$ compared with nearly 47 to $50 \%$ of the isolates from the blocks receiving no fungicide treatment. At the same time, we found no differences in growth rate, sporulation, or copper sensitivity between DMI-R and DMI-S isolates. Similarly, there were no differences in growth rate, sporulation, or copper sensitivity between isolates from the copper treated plots and those from the other delayed dormant treatment plots. Given that there were no differences in copper sensitivity or in vitro fitness, it stands to reason that copper sensitivity and compromised fitness had little to do with the absence of highly resistant isolates in plots treated with copper. A possible explanation could be that highly resistant isolates were not compromised in fitness, but simply devoting too many cellular resources to perpetuate the mechanisms of DMI resistance, such as multidrug efflux pumps, to deal with the influx of copper, a new toxin. However, the investigations needed to support such a theory are beyond the scope of the current study.

Interestingly, it is known that copper salts can affect spore production and viability in $V$. inaequalis (Cervantes and Gutierrez-Corona 1994; Montag et al. 2006). Low (1 mmol/liter) concentrations of copper sulfate can damage $V$. inaequalis conidial membranes and inhibit

Table 1. In vitro growth rates in the absence or presence of copper and in vitro sporulation for isolates of Venturia inaequalis with DMI resistance or sensitivity and from delayed dormant treatment programs

\begin{tabular}{|c|c|c|c|}
\hline $\begin{array}{l}\text { Delayed dormant treatment or DMI } \\
\text { resistance phenotype }\end{array}$ & $\begin{array}{l}\text { Mean growth of isolates } \\
\left.(\mu \mathrm{m} \mathrm{day})^{-1}\right)^{\mathrm{a}}\end{array}$ & $\begin{array}{l}\text { Mean growth of isolates on } 125 \mathrm{ppm} \\
\left.\text { copper }(\mu \mathrm{m} \mathrm{day})^{-1}\right)^{\mathrm{a}}\end{array}$ & $\begin{array}{l}\text { Mean sporulation of isolates in vitro } \\
\left(10^{4} \text { spores } \mathrm{ml}^{-1}\right)^{\mathrm{b}}\end{array}$ \\
\hline$\overline{\text { DMI-S }}$ & $426.1 \pm 11.8$ & $269.3 \pm 14.4$ & $40.6 \pm 1.2$ \\
\hline DMI-R & $435.8 \pm 10.1$ & $277.6 \pm 10.1$ & $40.0 \pm 1.2$ \\
\hline Untreated & $428.5 \pm 17.2$ & $265.1 \pm 20.8$ & $39.7 \pm 1.8$ \\
\hline Myclobutanil & $440.8 \pm 16.0$ & $295.0 \pm 20.3$ & $42.8 \pm 1.7$ \\
\hline Copper & $438.1 \pm 13.2$ & $280.2 \pm 20.8$ & $38.8 \pm 1.7$ \\
\hline Manganese & $415.3 \pm 15.3$ & $252.0 \pm 22.9$ & $40.4 \pm 1.6$ \\
\hline
\end{tabular}

a Mean growth rates of $V$. inaequalis isolates on potato dextrose agar and casitone yeast extract agar amended with $125 \mu \mathrm{g} \mathrm{ml}{ }^{-1} \mathrm{CuSO}_{4} \cdot 5 \mathrm{H}_{2} \mathrm{O} . \mathrm{Values}$ are means and standard errors of 88 isolates for each DMI resistance phenotype or 44 isolates from each delayed dormant treatment.

b Mean sporulation in vitro for $V$. inaequalis isolates on potato dextrose agar. Values are means and standard errors of 88 isolates for each DMI resistance phenotype or 44 isolates from each delayed dormant treatment. 
complete mitochondrial respiration in isolates with reduced fitness (Montag et al. 2006). The authors also found that concentrations of copper hydroxide at $25 \mathrm{mmol} / \mathrm{liter}$ had a similar effect on conidial viability in $V$. inaequalis (Montag et al. 2006). Indeed, we found that $V$. inaequalis isolates from the current study would not sporulate on CYE amended with copper sulfate (data not shown). Both copper compounds have a high degree of toxicity, but the increased toxicity on the part of copper sulfate has been attributed to its high solubility (Montag et al. 2006). However, a copper product with high water solubility could be ineffective as a delayed-dormant fungicide due to wet conditions during the early apple season. Hence, fairly waterinsoluble copper products such as those containing copper hydroxide are preferable for early season application in apples (Montag et al. 2006). The copper product Badge $\times 2$, which is $24.6 \%$ copper oxychloride and $22.9 \%$ copper hydroxide, was chosen for this study because it is a moderately insoluble copper fungicide and is formulated to resist weathering by rain. The rain fastness of Badge $\times 2$ could have contributed to the consistent effect on DMI sensitivity despite wetting following the application date in the 2012 trial.

A delayed-dormant treatment of myclobutanil (Rally 40WSP) did not affect the DMI sensitivity of isolates over two consecutive years of orchard trials. This was probably due to the inability of this delayed-dormant treatment to eliminate many population members because of the population's practical resistance to DMI fungicides (Cox et al. 2009, 2010, 2011). While one would concede that each DMI application increases the propensity for the development of resistance to DMI fungicides while populations are still sensitive (Ishii 2006), further applications of DMIs may not greatly impact the DMI sensitivity of $V$. inaequalis populations when it exhibits a high level of practical resistance. Consequently, in this experiment the myclobutanil delayed-dormant treatment simply served as a comparison standard, or check, that DMI is resistance is still present.

During both years of the study, we tested the sensitivity of the $V$. inaequalis isolates to dodine, to which the population used herein was not resistant (Cox et al. 2012). There were no significant differences in dodine sensitivity for $V$. inaequalis isolates collected from the four delayed-dormant treatments. Additionally, the majority of isolates collected from delayed dormant chemical treatments were sensitive to dodine ( $\% \mathrm{RG}<50 \%)$, which is consistent with the previously reported sensitivity to dodine for this orchard population (Cox et al. 2012). The lack of an effect of the copper treatment on dodine sensitivity may be due to a lack of resistant members in the population. The impact of a delayed dormant treatment on $V$. inaequalis population sensitivity may only be realized in the context of practical resistance. This would especially be the case if there were no members with high levels of dodine resistance. As discussed earlier for myclobutanil sensitivity following copper application, isolates with high \% RG values (i.e., \%RG > 90) were the most impacted by delayed-dormant treatments of copper. In regards to dodine sensitivity, there were few to no isolates with $\% \mathrm{RG}>90$ on dodine-amended medium (data not shown). Hence, it's not surprising that there was no significant impact of copper on dodine sensitivity.

The manganese treatment program impacted the DMI sensitivity of the $V$. inaequalis isolates in 2011, but the effect was not observed in 2012. It is not currently known if apple scab ascospore formation or conidial viability is inhibited by manganese exposure in the same manner as reported for copper (Montag et al. 2006), and knowledge of ascospore maturation in any ascomycete due to manganese treatment is limited. Manganese sulfate has been demonstrated to inhibit Saccharomyces cerevisiae ascospore production at doses above 0.0020 M (McClary et al. 1959). Similarly, a decrease of ascospore growth and viability of the lichen, Hypogymnia physodes, has been observed with an increasing manganese concentration in tree bark (Hauck et al. 2001, 2002). Given the lack of information on the effects of manganese, further investigation is needed to address the potential benefits of this metal cation and address possible inconsistency in performance. The inconsistency of the manganese treatment program in affecting the DMI sensitivity of single lesion conidial $V$. inaequalis isolates between years could be attributed to differences in seasonal weather conditions. For example, there was 0 versus $3 \mathrm{~cm}$ of rainfall in the three days prior to the 2011 (8 April) and 2012 (8 March) delayed dormant application date, respectively, and 8 versus $24 \mathrm{~h}$ of leaf wetness in the three days following applications in 2011 and 2012, respectively. Unlike the copper product Badge $\times 2$, which is formulated for some rain fastness, F2 Industries has formulated and markets their manganese product ( $\mathrm{F} 2$ permanganate) to primarily be used as a water sanitizer with high water solubility (http:// www.f2ind.com/potable-water.html). Such high water solubility could diminish the persistence of $\mathrm{F} 2$ permanganate on treated plant tissue. Even with the minor rain event ( $3 \mathrm{~cm}$ rainfall), it is possible that the product would have washed off or been diluted. This is consistent with observations for other soluble metal cation products including highly soluble copper products, which have reduced persistence on treated tissues (Montag et al. 2006). In 2012, the survival of DMIresistant $V$. inaequalis isolates would have been higher if the manganese product was not as effective as the copper treatment or if the former had been washed away in the wetting following application.

In the present study, we demonstrated that a delayed-dormant application of copper consistently increased DMI sensitivity in a DMIresistant orchard population. Hence, delayed-dormant treatments of copper fungicides could be used as a means of resistance management for $V$. inaequalis. Aside from copper, the manganese sanitation product may have potential for resistance management, although the effect was not consistent. Understanding the relationship between chemical management practices and the sensitivity of $V$. inaequalis populations to various fungicide chemistries throughout the production season will continue to be crucial for the identification and future implementation of effective resistance management strategies.

\section{Acknowledgments}

This work was supported in part by funds appropriated to New York State Agricultural Experiment Station, Cornell University. We would like to thank Jessica Raes, Charlotte Lehman, Kathryn Abbott, Michael Rosato, Nicole Gottschall, and Juliana Freier for their assistance in the collection and preparation of and evaluation of isolates.

\section{Literature Cited}

Agrios, G. N. 2005. Pages 501, 504-507 in: Plant Pathology, 5th Ed. Elsevier Academic Press, Burlington, MA.

Cervantes, C., and Gutierrez-Corona, F. 1994. Copper resistance mechanisms in bacteria and fungi. FEMS Microbiol. Rev. 14:121-137.

Cox, K. D., Villani, S. M., Ellis, M. A., Poon, C. K., and Craig-Kuhn, M. C. 2009 Evaluation of fungicides in an orchard with a DMI-resistant apple scab population, 2008. Plant Dis. Manage. Rep. 3:PF039.

Cox, K. D., Villani, S. M., and Raes, J. J. 2010. Evaluation of fungicides for control of apple scab in a 'McIntosh' 'Cortland' orchard with a DMI-resistant apple scab population, 2009. Plant Dis. Manage. Rep. 4:PF019.

Cox, K. D., Villani, S. M., and Raes, J. J. 2011. Evaluation of fungicides for control of apple scab in a 'McIntosh' 'Cortland' orchard with a DMI-resistant apple scab population, 2010. Plant Dis. Manage. Rep. 5:PF032.

Cox, K. D., Villani, S. M., and Ramaekers, L. 2012. Prevalence of dodine resistance in Venturia inaequalis populations in the northeastern United States following renewed use of Syllit for the management of apple scab. Phytopathology 102:S26.

Gadoury, D. M., and MacHardy, W. E. 1982. A model to estimate the maturity of ascospores of Venturia inaequalis. Phytopathology 72:901-904.

Gilpatrick, J. D. 1982. Case study 2: Venturia on pome fruit and Monilinia on stone fruits. Pages 195-206 in: Fungicide resistance in Crop Protection. J. Dekker and S. G. Georgopoulos, eds. Pudoc, Wageningen.

Hauck, M., Jung, R., and Runge, M. 2001. Relevance of element content of bark for the distribution of epiphytic lichens in a montane spruce forest affected by forest dieback. Environ. Pollut. 112:221-227.

Hauck, M., Paul, A., Mulack, C., Fritz, E., and Runge, M. 2002. Effects of manganese on the viability of vegetative diaspores of the epiphytic lichen Hypogymnia physodes. Environ. Exp. Bot. 47:127-142.

Holb, I. J., Heijne, B., and Jeger, M. J. 2003. Summer epidemics of apple scab: The relationship between measurements and their implications for the development of predictive models and threshold levels under different disease control regimes. J. Phytopathol. 151:335-343.

Ishii, H. 2006. Impact of Fungicide Resistance in Plant Pathogens on Crop Disease Control and Agricultural Environment. Jarq-Jpn. Agr. Res. Q. 40:205-211.

Jama, L., and Lateur, M. 2007. Strategies to Reduce Copper Use in Organic Apple Production. Acta. Hort. 737. ISHS 2007:113-120.

Köller, W. 1991. Fungicide resistance in plant pathogens. Pages 679-720 in: CRC Handbook of Pest Management in Agriculture, 2nd edition. CRC Press, Boca Raton, FL. 
Köller, W., Parker, D. M., Turechek, W. W., Avila-Adame, C., and Cronshaw, K. 2004. A two-phase resistance response of Venturia inaequalis populations to the QoI fungicides kresoxim-methyl and trifloxystrobin. Plant Dis. 88:537-544.

Köller, W., Wilcox, W. F., Barnard, J., Jones, A. L., and Braun, P. G. 1997. Detection and quantification of resistance of Venturia inaequalis populations to sterol demethylation inhibitors. Phytopathology 87:184-190.

Köller, W., Wilcox, W. F., and Jones, A. L. 1999. Quantification, persistence, and status of dodine resistance in New York and Michigan orchard populations of Venturia inaequalis. Plant Dis. 83:66-70.

Lesniak, K. E., Proffer, T. J., Beckerman, J. L., and Sundin, G. W. 2011. Occurrence of QoI resistance and detection of the G143A mutation in Michigan populations of Venturia inaequalis. Plant Dis. 95:927-934.

Loper, J. E., Henkels, M. D., Roberts, R. G., Grove, G. G., Willet, M. J., and Smith, T. J. 1991. Evaluation of streptomycin, oxytetracylcine, and copper resistance of Erwinia amylovora isolated from pear orchards in Washington State. Plant Dis. 75:287-290.

Ma, Z., and Michailides, T. J. 2005. Advances in understanding molecular mechanisms of fungicide resistance and molecular detection of resistant genotypes in phytopathogenic fungi. Crop Prot. 24:853-863.

MacHardy, W. E. 1996. Pages 5-9, 385-387 in: Apple Scab - Biology, Epidemiology, and Management. APS Press, St. Paul, MN.

MacHardy, W. E., Gadoury, D. M., and Gessler, C. 2001. Parasitic and biological fitness of Venturia inaequalis: relationship to disease management strategies. Plant Dis. 85:1036-1051
McClary, D. O., Nulty, W. L., and Miller, G. R. 1959. Effect of potassium versus sodium in the sporulation of Saccharomyces. J. Bacteriol. 78:362-368.

Merwin, I. A., Brown, S. K., Rosenberger, D. A., Cooley, D. R., and Berkett, L. P. 1994. Scab-resistant apples for the northeastern United States: new prospects and old problems. Plant Dis. 78:4-10.

Montag, J., Schreiber, L., and Schönherr, J. 2006. An in vitro study of the nature of protective activities of copper sulphate, copper hydroxide and copper oxide against conidia of Venturia inaequalis. J. Phytopathol. 154:474-481.

Norelli, J. L., Jones, A. L., and Aldwinckle, H. S. 2003. Fire blight management in the twenty-first century: using new technologies that enhance host resistance in apple. Plant Dis. 87:756-765.

Olaya, G., and Koller, W. 1999. Baseline sensitivities of Venturia inaequalis populations to the strobilurin fungicide kresoxim-methyl. Plant Dis. 83: 274-278.

Pfeufer, E. E., and Ngugi, H. K. 2012. Orchard factors associated with resistance and cross resistance to sterol demethylation inhibitor fungicides in populations of Venturia inaequalis from Pennsylvania. Phytopathology 102:272-282.

Singer, S. D., and Cox, K. D. 2010. The reemergence and management of currant cane dieback in the northeastern United States. Plant Dis. 94: 1283-1289.

Sutton, D. K., MacHardy, W. E., and Lord, W. G. 2000. Effects of shredding or treating apple leaf litter with urea on ascospore dose of Venturia inaequalis and disease buildup. Plant Dis. 84:1319-1326. 